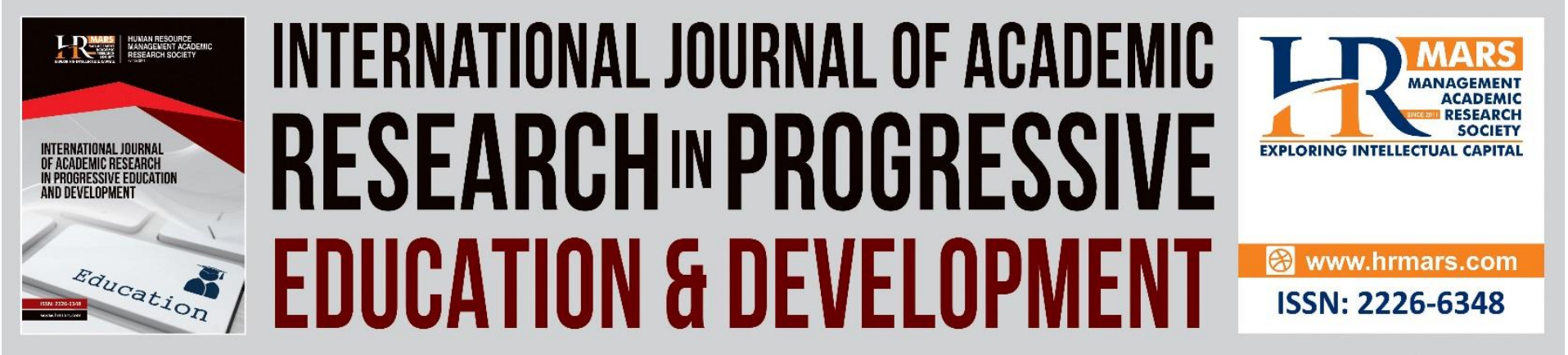

\title{
Towards Efficient Monitoring of Online Distance Learning with Google Meet Intelligent Attendance (GMiA2021)
}

Zahari Md Rodzi, Wan Normila Mohamad, Muhamad Helmi Muhamad Khair, Wan Asma Wan Nasrudin, Annas Mustaffa Aminuddin, Wan Norwidayawaty Mohammad, Hisham Abd Rahman

To Link this Article: http://dx.doi.org/10.6007/IJARPED/v10-i3/10887

DOI:10.6007/IJARPED/v10-i3/10887

Received: 05 July 2021, Revised: 07 August 2021, Accepted: 30 August 2021

Published Online: 26 September 2021

In-Text Citation: (Rodzi et al., 2021)

To Cite this Article: Rodzi, Z. M., Mohamad, W. N., Khair, M. H. M., Nasrudin, W. A. W., Aminuddin, A. M., Mohammad, W. N., \& Rahman, H. A. (2021). Towards Efficient Monitoring of Online Distance Learning with Google Meet Intelligent Attendance (GMiA2021). International Journal of Academic Research in Progressive Education and Development, 10(3), 993-1001.

Copyright: (C) 2021 The Author(s)

Published by Human Resource Management Academic Research Society (www.hrmars.com)

This article is published under the Creative Commons Attribution (CC BY 4.0) license. Anyone may reproduce, distribute, translate and create derivative works of this article (for both commercial and non-commercial purposes), subject to full attribution to the original publication and authors. The full terms of this license may be seen

at: http://creativecommons.org/licences/by/4.0/legalcode

Vol. 10(3) 2021, Pg. 993 - 1001

Full Terms \& Conditions of access and use can be found at http://hrmars.com/index.php/pages/detail/publication-ethics 


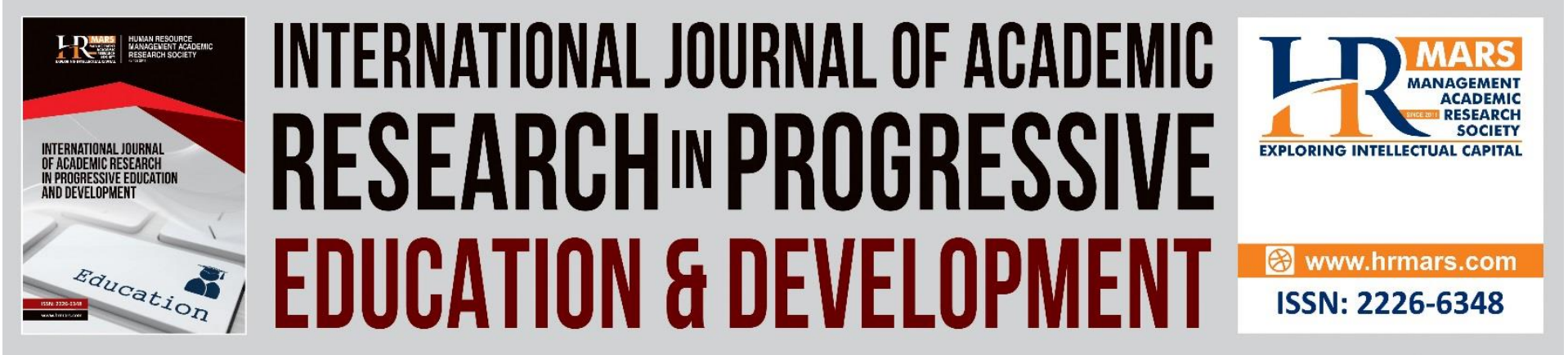

\title{
Towards Efficient Monitoring of Online Distance Learning with Google Meet Intelligent Attendance (GMiA2021)
}

\author{
Zahari Md Rodzi ${ }^{1}$, Wan Normila Mohamad², Muhamad Helmi \\ Muhamad Khair ${ }^{3}$, Wan Asma Wan Nasrudin ${ }^{4}$, Annas Mustaffa \\ Aminuddin $^{5}$, Wan Norwidayawaty Mohammad ${ }^{6}$, Hisham Abd \\ Rahman $^{7}$
}

1,5 Faculty of Computer and Mathematical Sciences, ${ }^{2}$ Faculty of Business and Management, ${ }^{3}$ Department of Law, ${ }^{4}$ Faculty of Accountancy Universiti Teknologi MARA Cawangan Negeri Sembilan, Kampus Seremban 70300 Seremban, Negeri Sembilan, Malaysia, ${ }^{6}$ Development Monitoring Division, Implementation Coordination Unit, Prime Minister Department, 62502 Putrajaya, Malaysia, ${ }^{7}$ DCP Architects Sdn. Bhd., Bandar Seri Permaisuri, 56000 Kuala Lumpur, Malaysia

Email: wanno794@uitm.edu.my

\begin{abstract}
The use of Google Meet has grown since the Covid-19 pandemic hits the world. Google Meet is an effective platform for delivering online education. Currently, Google Meet attendance sheets are only available through ' $G$ Suite Enterprise for Education', requiring a subscription fee. For other user types, the Google Meet attendance extension is a good alternative. However, it comes with several disadvantages, including the inability to identify absent students and summarise the monthly attendance of students. As a solution, Google Meet Intelligent Attendance (GMiA2021) was developed, which includes a more systematic and easy-to-use multi-functional coordination and help track student absenteeism. This intelligent attendance system can connect directly to WhatsApp to remind students of class absences. GMiA2021 also allows lecturers to keep proof of absence and documents provided by the students and prepare monthly attendance reports, in line with academic rules to enable students with $80 \%$ attendance to sit for the examination. GMiA2021 is expected to help efficient monitoring of the student's attendance and collaborations with university academic administration for a systematic attendance system.
\end{abstract}

Keywords: Google Meet, Smart Attendance System, Educators and Students, Online Distance Learning, Higher Learning Institutions 


\section{Introduction}

The global outbreak of Covid-19 has had an unprecedented impact on the education sector, leading to the closure of educational institutions (OECD 2020). Consequently, Malaysian higher learning institutions are prompted to conduct teaching and learning sessions from remote locations, primarily through online platforms which limit physical and face-to-face meetings with students. In this new environment, a dependable and efficient system for monitoring, verifying, and ensuring that students attend the online scheduled sessions is critical in assessing their academic performance. However, the current attendance system in Microsoft Teams, Google Forms, Google Classroom, and the uFuture system is relatively inefficient for the lecturers to check on absent students or other issues. Instead, the lecturers must manually check the attendance to detect the absentees for follow-up purposes, resulting in inefficient time management in class. Observation also discovered several other problems with the current attendance system. Such as its lack of accuracy, the inconvenience of calling the students' names and filling in a form each time they attend class, and the difficulty of procedures for collecting and recording excuses of absence from absentees. This project aspires to address the said issues by introducing a new system that allows lecturers to monitor attendance more efficiently in an online teaching and learning environment. In this light, the main objective of this project is to develop a less-hassle and integrative attendance tracking system. It is anticipated that this particular system may serve the following functions, (a) manage students' absenteeism, (b) calculate the amount of time spent in class, (c) link letter of excuses to the attendance sheet, (d) send WhatsApp reminder, (e) facilitates the task of attendance taking, and (f) serve as an efficient communication tool between students, lecturers, and faculties for supervision purposes. The remainder of this paper entails other crucial information about this project. It commences with a review of the literature pertaining to Covid-19 and the shift of teaching and learning approach as well as Google Meet and attendance tracking. It is followed by the methodology section, outlining the step-by-step guide undertaken to develop and use GMiA 2021. This section is followed by a discussion on the project outcomes, the product's novelty, and a conclusion.

\section{Literature Review}

\section{Covid-19 and Shift of Teaching \& Learning Approach}

The Covid-19 pandemic has become a global and national health crisis for most countries worldwide (Jena, 2020). It is an infectious disease caused by a recently identified coronavirus. Most patients will experience mild to moderate respiratory illness and may recover without the need for special treatment. However, people with underlying medical conditions such as cancer, diabetes, and chronic respiratory disease are more likely to develop severe illnesses. One of the most preferred methods for preventing the spread of Covid-19 is through containment measures, which are being implemented across the globe (De Brouwer et al., 2020). This is also in line with World Health Organisation (2020)'s recommendation that large scale physical distancing and movement restrictions can stop the Covid-19 transmission by limiting contact between people.

While effective, these measures also have a negative impact on individuals, communities, and various industries, including the education sector. According to Lokanath et al (2020), the movement restriction measures have disproportionately disrupted the worldwide educational system. On this note, El Khatib and Chizzotti (2020) reported that 61 countries across Africa, Asia and Europe (among others) had closed their schools and universities. Like 
other countries, the Malaysian government has issued a movement control order (MCO) to control the spread of Covid-19, but such an initiative has also dampened the learning institutions' operational activities (Abdullah et al., 2020; Chinazzi et al., 2020). Following this, the Malaysian Ministry of Higher Education had instructed all private and government-funded educational institutions to conduct teaching and learning via online platforms (Yiswaree, 2020; Bernama, 2021). Consequently, the closure of all learning institutions had dramatically increased the use of web-based learning platforms such as Google Meet, Google Classroom, Microsoft Teams, Cisco Webex, Youtube and Zoom Cloud Meeting (Kamal et al., 2020).

\section{Google Meet and Attendance Monitoring}

Google Meet is a platform for groups of people to communicate or conduct meetings virtually. The goal is to make enterprise-grade video conferencing available practically to everyone. On top of its standard features (e.g. polls and live streaming), users can also use its advanced features, which allow for meetings with a maximum of 250 participants and live-streaming to up to 100,000 viewers within a domain. Be that as it may, one feature that is relevant to online class monitoring is attendance tracking. Khan et al (2020) emphasised the importance of attendance monitoring as a component of an effective organisational information system. Likewise, in an academic setting, attendance records are critical for lecturers to monitor the students' performance and determine their eligibility to sit for the final exam. Additionally, Elisabeth et al (2019) contended that attendance generally reflects students' level of engagement and commitment to their course. Prior research has demonstrated that students (especially those who are academically weak) tend to gain better marks when they attend classes more regularly; however, additional research is needed to substantiate this premise (Muir, 2009).

The standard method of recording the attendance requires the students to sign the attendance sheet personally each time they attend face-to-face meetings. This conventional method evolved into a more convenient and time-saving online class attendance system in light of the ever-changing educational environment. As regards this feature, Google Meet's online attendance tracking is only available in certain selected Google Meet editions, such as Google Workspace Essentials, Enterprise Essentials, Business Plus, and Education Plus. For ordinary users, they can still use the Google Chrome extensions or require the students to fill up a Google Form. However, the information in the attendance report contains limited details of participants, such as names, emails, and timestamps for when they joined and left the call. In view of the above, it is submitted that an online attendance system should be more practical, comprehensive, and inclusive. In other words, it should be comprised of automated processes that generate attendance reports, instantly notify relevant students of their absence, and keep any supporting documents in one place. This is to ensure that recording and reporting on student attendance are more efficient and well-organised.

\section{Methodology}

The discussion in the preceding section motivates the project team to develop GMiA2021. Essentially, GMiA2021 is an Excel-based spreadsheet attendance system developed using technical knowledge of Excel's tools and programming language. Figure 1 illustrates an overall step-by-step guide in the development of GMiA2021. 


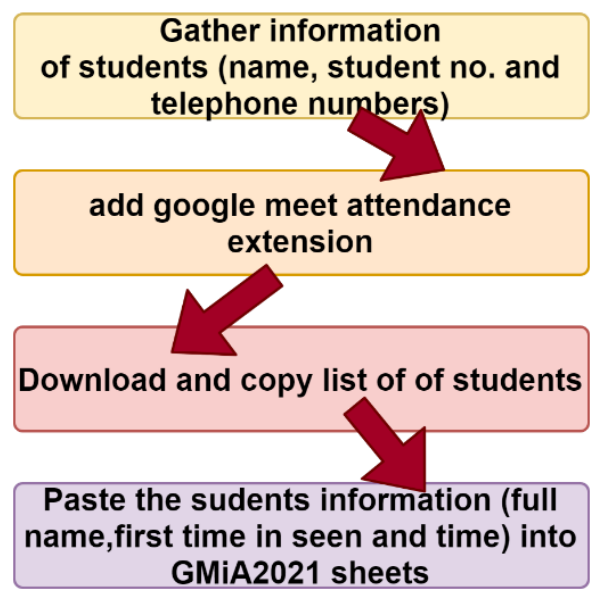

Figure 1. The Methodology of GMiA2021

\section{STEP 1. Gathering Student's Information (Google Form, uFuture, SIMS)}

The first step is to collect the students' personal data. These may include details such as their full names, telephone numbers, identification numbers, and email addresses (if necessary). This exercise should ideally be conducted at the beginning of class, during the first week of the semester, by using Google Forms, WhatsApp, or email. The form containing these details will then be converted into excel format for the purpose of systematic information labelling.

\section{STEP 2. Google Meet Attendance Extension and Download Attendance Report}

The second step is to install Google Meet Attendance Extension. From the Google Chrome Webstore, search Google Meet Attendance List from Bluexpixelgroup.com (as shown in Figure 2 below). This extension is preferable for this project because it is highly recommended by

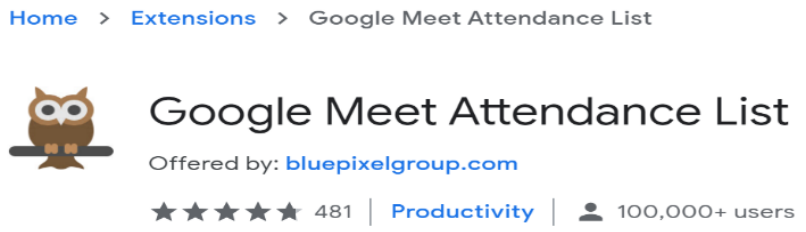

previous users (due to its high rating). It is also user-friendly as it includes a feature that automatically generates a pop-up notification to download the attendance sheet, following the conclusion of the Google Meet sessions. The attendance report generated ("Export as CSV") from this phase is crucial as it contains students' information that will be used in the following step.

Figure 2. The Google Meet Attendance List (Extension) by Bluepixelgroup.com

\section{STEP 3. Copy and Paste Students' Information}

The third step is to copy the students' information downloaded from the previous step (saved as an Excel document). Figure 3 below is a snapshot of the Excel document, detailing the "First Seen (the exact time students check in the Google Meet session) and the "Time in Call (the total number of hours spent in class)". 
INTERNATIONAL JOURNAL OF ACADEMIC RESEARCH IN PROGRESSIVE EDUCATION AND DEVELOPMENT

Vol. 10, No. 3, 2021, E-ISSN: 2226-6348 @ 2021 HRMARS

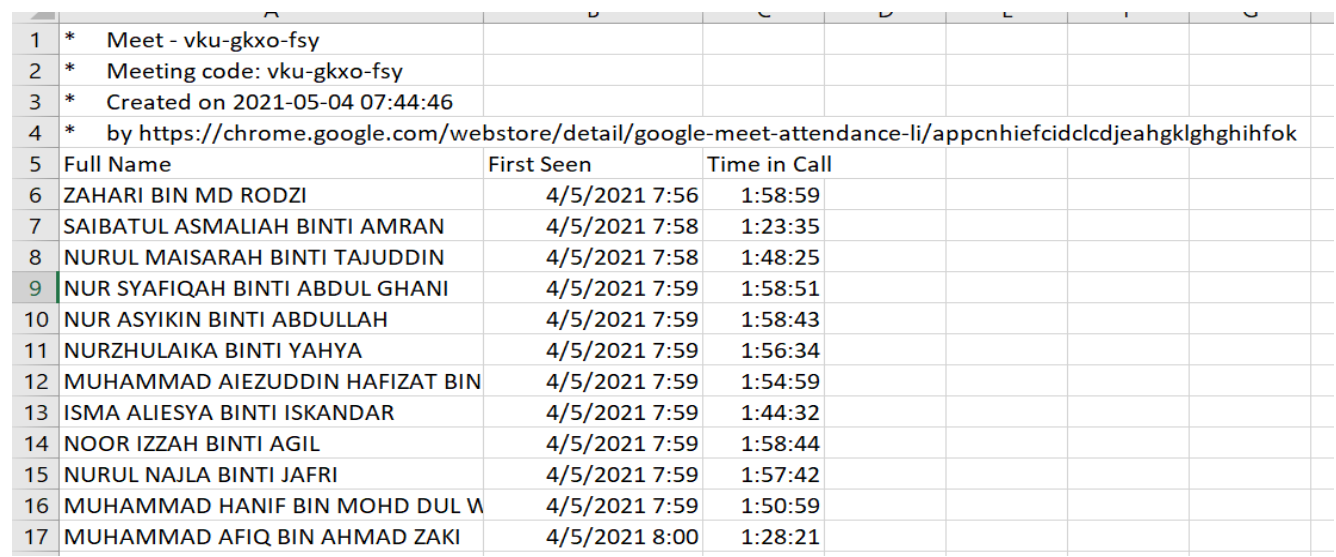

Figure 3. The Google Meet Attendance Report by Bluepixelgroup.com

Once the information is copied, the next step is to paste the same information into the relevant column of GMiA2021. Figure 4 below depicts a snapshot of this step. As shown, Column 1 of GMiA2021 is for Week 1, which is generated based on the information from Figure 3. The difference is that GMiA2021 produces more detailed information about the students.

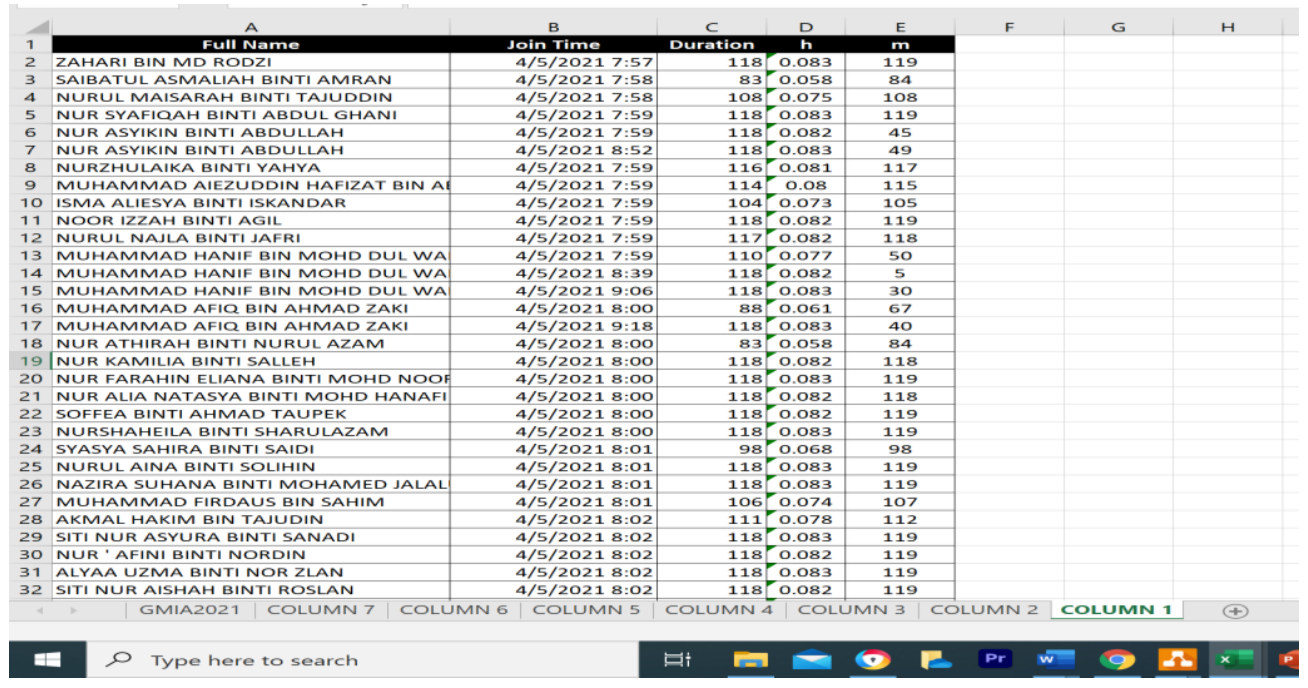

Figure 4. Paste the information into a relevant column of GMiA2021

\section{Step 4. Visit the Main Layout of GMiA2021}

The final step is to visit the main layout of GMiA2021. As illustrated in Figure 5, GMiA2021 generates and presents concise information about the students' attendance. This (colourful) layout enables the lecturers to have an overview of the students' attendance and quickly extract any relevant information (e.g. the total number of present students). 


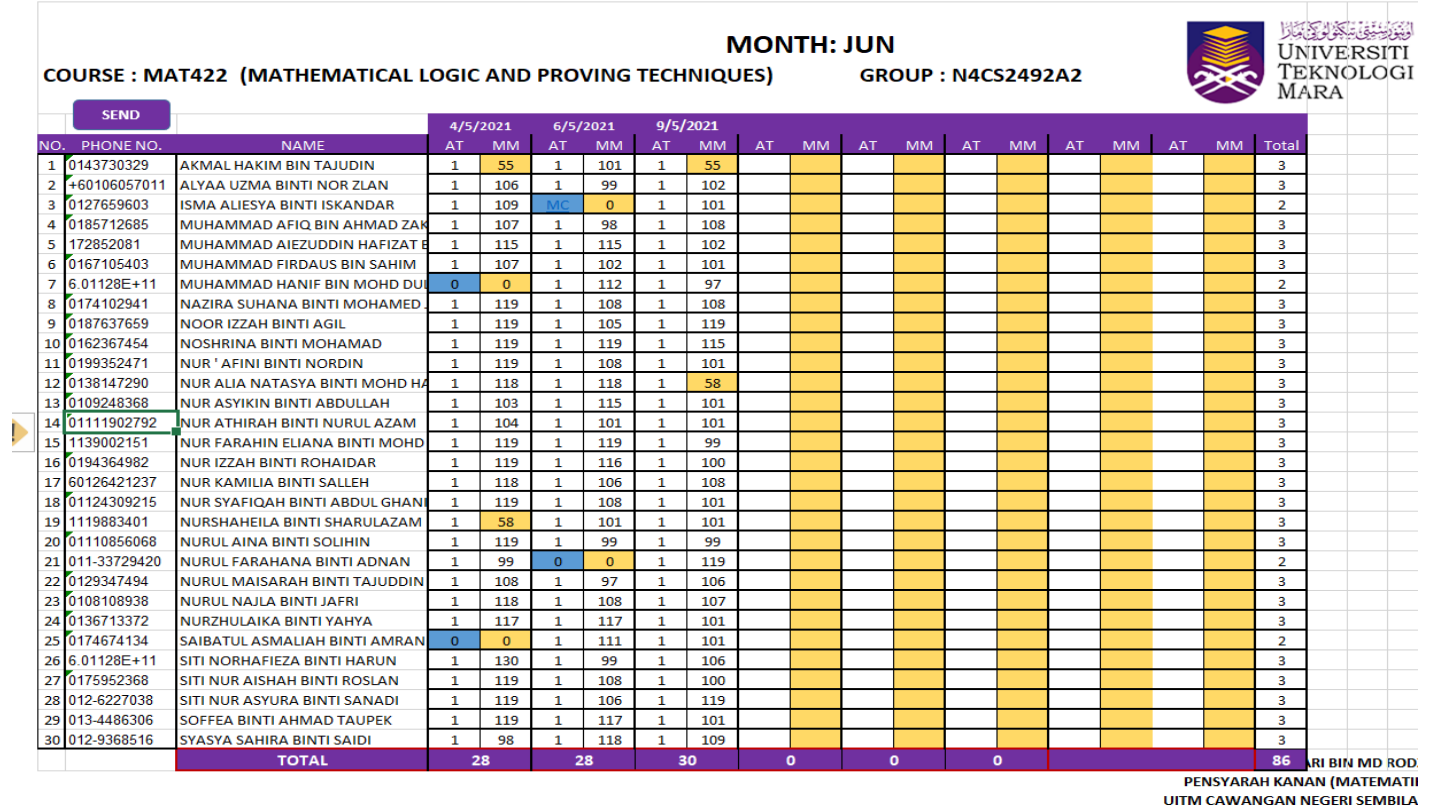

Figure 5. The Main GMiA2021 Layout

Additionally, the novelty of GMiA2021 lies in its unique features (as shown in Figure 6 below) that are not shared by any other existing attendance tracking system. Among these features is the "Send" function, allowing lecturers to relay WhatsApp reminders to absent students. The lecturers can also keep relevant documents (e.g. medical certification) from absent students through GMiA2021. This function assists lecturers in keeping and managing the relevant documents in one place, which is extremely useful for audit purposes. A wellorganised system for document management (transpired via this function) is also in accordance with the Academic Affairs Department's instructions.

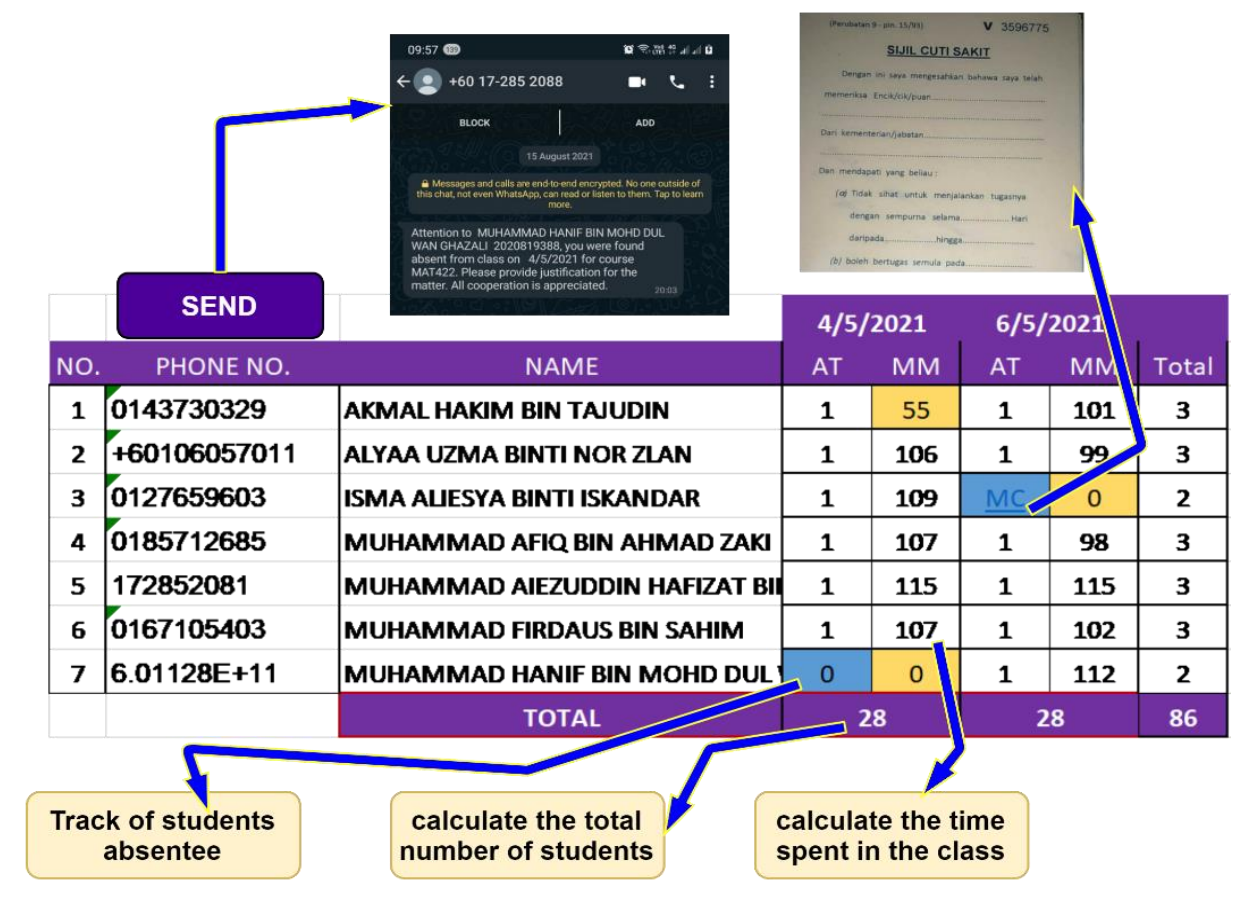

Figure 6. The features of main sheet of GMiA2021 
DEVELOPMENT

Vol. 10, No. 3, 2021, E-ISSN: 2226-6348 ㄷ 2021 HRMARS

\section{Project Outcomes, Uniqueness and Marketability}

The expected outcomes of GMiA2021 are numerous. Firstly, it helps lecturers to have a better experience with Google Meet, particularly with the attendance management system. Remote users, particularly lecturers who use GMiA2021, will find it easier to manage from home lives. Secondly, an integrated attendance management system such as GMiA2021 also provides the flexibility, ease of use and access across devices and platforms that modern higher education institutions require.

The marketability of GMiA2021 lies in its unique features, which will help educators manage their attendance tracking system better. The following are some of the features that distinguish GMiA2021 as an intelligent attendance management system from its counterparts. Firstly, GMiA2021 identifies student absentees and links scanned copies of documents evidencing their absence (e.g. medical certificates) to the attendance sheet. These documents are also kept in the system. Secondly, GMiA2021 can send WhatsApp messages to students to remind them of their class absence. This feature has yet to be integrated into any existing attendance tracking platforms, thereby establishing the novelty and uniqueness of this product. Thirdly, GMiA2021 displays the number of minutes spent by students and their instructors in class. This feature will allow educators to monitor and keep track of the time spent with them.

GMiA2021 stands out due to its unique features that no other existing attendance tracking system has. With the current work-from-home situation, remote users across the field are looking for a reliable tool for attendance management, time-tracking with some other analytics features and configurations - which in an academic setting, can be accomplished with GMiA2021. Additionally, most educational institutions (schools, public and private higher learning institutions) use an online attendance tracking system. In this light, GMiA2021 can be further commercialised to teachers and lecturers in these institutions. In other words, the product's target user is not limited to UiTM staff per se but also includes a diverse group of potential users from other educational institutions.

\section{Conclusion}

The objective of this project is to create a more convenient and integrated attendance monitoring system. In order to achieve the said objective, this project has developed GMiA2021 by combining technical knowledge of Excel's tools, the programming language and a third-party application available on Google Chrome. It is a more systematic and user-friendly multi-functional coordination system that assists in the tracking of student absence. This sophisticated attendance system may communicate directly with students' WhatsApp accounts to notify them of class absences. Additionally, GMiA2021 enables educators to keep track of students' absences and documentary evidence, as well as generate monthly attendance reports in accordance with academic standards, allowing students with an attendance rate of at least $80 \%$ to sit for the final examination. As GMiA2021 is a relatively new and innovative product, the team recommends that a survey be conducted in the future to ascertain its effectiveness and make any necessary improvements. Regardless, the team anticipates that this product will assist the educators in monitoring student attendance effectively and collaborating with university academic administration to establish a systematic attendance system. 


\section{References}

Abdullah, S., Mansor, A. A., Napi, N. N. L. M., \& Mansor, W. N. W., Ahmed, A. N., Ismail, M., \& Ramly, Z. T. A. (2020). Air quality status during 2020 Malaysia Movement Control Order (MCO) due to 2019 novel coronavirus (2019-nCoV) pandemic. Science of The Total Environment, 729, 139022.

Bernama. (2021). Education Ministry: Home-based teaching and learning to continue nationwide until Aug 31.4 Malay Mail. https://www.malaymail.com/news/malaysia/2021/07/17/education-ministry-homebased-teaching-and-learning-to-continue-nationwide/1990664.

De Brouwer, E., Raimondi, D., \& Moreau, Y. (2020). Modeling the COVID-19 outbreaks and the effectiveness of the containment measures adopted across countries. medRxiv.

El Khatib, A. S., \& Chizzotti, A. (2020). Aulas por videoconferência: uma solução para o distanciamento social provocado pela Covid-19 ou um grande problema? Uma solução para o distanciamento social provocado pela COVID-19 ou um grande problema? Revista EDaPECl, 20(3), 26-45.

Jena, P. K. (2020). Challenges and Opportunities created by Covid-19 for ODL: A case study of IGNOU. International Journal for Innovative Research in Multidisciplinary Field (IJIRMF), 6.

Kamal, A. A., Shaipullah, N. M., Truna, L., Sabri, M., \& Junaini, S. N. (2020). Transitioning to online learning during COVID-19 Pandemic: Case study of a Pre-University Centre in Malaysia. International Journal of Advanced Computer Science and Applications, 11(6).

Khan, A., Jhanjhi, N. Z., \& Humayun, M. (2020). Secure Smart and Remote Multipurpose Attendance Monitoring System. EAI Endorsed Transactions on Energy Web, 7(30), e5.

Matteo, C., Davis Jessica, T., Marco, A., Corrado, G., Maria, L., \& Stefano, M. (2020). Piontti Ana Pastore y, Mu Kunpeng, Rossi Luca, Sun Kaiyuan, et al. The effect of travel restrictions on the spread of the 2019 novel coronavirus (covid-19) outbreak. Science.

Mishra, L., Gupta, T., \& Shree, A. (2020). Online teaching-learning in higher education during lockdown period of COVID-19 pandemic. International Journal of Educational Research Open, 1, 100012.

Moores, E., Birdi, G. K., \& Higson, H. E. (2019). Determinants of university students' attendance. Educational Research, 61(4), 371-387.

Muir, J. (2009). Student attendance: is it important, and what do students think?. CEBE Transactions: Center for Education in the Built Environment (issn: 1745-0322), 6, 50-69.

OECD. (2020), Education at a Glance 2020: OECD Indicators, OECD Publishing, Paris.

Palansamy, Y. (2020) Higher Education Ministry: All university lectures to be online-only until end 2020, with a few exceptions. Malay Mail.

https://www.malaymail.com/news/malaysia/2020/05/27/higher-education-ministryall-university-lectures-to-be-online-only-until-e/1869975. 